\title{
Is totally laparoscopic gastrectomy without prophylactic drains feasible for patients with distal gastric cancer? The experience of China National Cancer Center
}

\section{hao liu ( $\square$ yajuhao_ab@163.com )}

Peking Union Medical College Hospital https://orcid.org/0000-0001-5809-6824

\section{Peng Jin}

Chinese Academy of Medical Sciences and Peking Union Medical College

\section{Quan Xu}

Chinese Academy of Medical Sciences and Peking Union Medical College

\section{Yibin Xie}

Chinese Academy of Medical Sciences and Peking Union Medical College

\section{Fuhai Ma}

Chinese Academy of Medical Sciences and Peking Union Medical College

\section{Shuai Ma}

Chinese Academy of Medical Sciences and Peking Union Medical College

\section{Yantao Tian}

Chinese Academy of Medical Sciences and Peking Union Medical College

\section{Research}

Keywords: Gastric cancer, Totally laparoscopic gastrectomy, Prophylactic drainage

Posted Date: April 24th, 2020

DOI: https://doi.org/10.21203/rs.3.rs-21343/v1

License: (9) (i) This work is licensed under a Creative Commons Attribution 4.0 International License. Read Full License 


\section{Abstract \\ Background}

Prophylactic drains have been used to remove intraperitoneal collections and to detect complications early in open surgery. In the last decades, Gastric cancer minimally invasive surgery has been widely carried out throughout the world. However, little has been reported on routine prophylactic abdominal drainage after totally laparoscopic distal gastrectomy. To evaluate the feasibility of without prophylactic drains in totally laparoscopic distal gastrectomy in selective patients.

\section{Methods}

Data of distal gastric cancer patients underwent totally laparoscopic distal gastrectomy with and without prophylactic drainage at China National Cancer Center/Cancer Hospital from February 2018 to August 2019 were reviewed. The outcomes of patients with and without a prophylactic drainage were compared.

\section{Results}

A total of 420 patients who underwent surgery for gastric cancer were identified; of these, 88 patients who received totally lapaoscopic distal gastrectomy were included. The incidence of concurrent illness was higher in the drain group, ( $48.8 \%$ vs. $27.7 \%, p=0.041)$. The overall postoperative complication rate was $19.5 \%$ in the drain group $(n=47)$, and $10.6 \%$ in the no-drain group $(n=41)$, there were no significant differences between two groups $(p>0.05)$. The need for percutaneous catheter drainage (PCD) was also not significantly different between groups $(9.8 \%$ vs. $6.4 \%, p=0.700)$. However, patients with larger BMI ( $\geq$ $29)$ are prone to postoperative complications $(p=0.042)$. In addition, more operating time cost in the drain group than in the no-drain group (188.10 $\pm 38.89 \mathrm{~min}$ vs. $164.30 \pm 36.97 \mathrm{~min}, \mathrm{p}<0.05)$. The number of days after surgery until the initiation of soft diet $(5.34 \pm 2.27$ days vs. $4.17 \pm 2.13$ days, $p<0.05)$ and first flatus ( $4.29 \pm 1.45$ days vs. $3.55 \pm 1.83$ days, $p=0.041$ ) were greater in the drain group.

\section{Conclusions}

Without prophylactic drainage may reduce surgery time and result in faster recovery. Routine prophylactic drains are not necessary in selective patients. A prophylactic drain may be useful in patients at higher risk.

\section{Background}

In recent ten years, gastric cancer is still one of the most frequently occurring malignancies worldwide. In 2017, there were about 1 million new cases of gastric cancer worldwide, which was the fifth most common malignancy, and the death rate was 783,000 , which was the third highest malignant tumor (1).In 
China, it was estimated that there were 677,000 new gastric cancer cases in China in 2015, accounting for half of the new gastric cancer cases in the world (2).

In 1994, Kitano reported the first case of laparoscopic assisted distal gastrectomy(LADG) with D2 lymphadenectomy (3), the recent South Korea multi-center clinical study also confirmed the operation was safe and effective treatment method (4), with the development of surgical instruments and the progress of technology, early gastric cancer minimally invasive surgery has been widely carried out throughout the world. Meanwhile, the interim results of class 01 clinical trial led by China southern hospital showed that the efficacy of laparoscopic surgery for advanced distal gastric cancer was comparable to that of open surgery (5).

With the development of laparoscopic surgery for gastric cancer, many surgeons begin to use totally laparoscopic surgery for distal gastric cancer, compared with laparoscopic assisted surgery, totally laparoscopic distal gastrectomy (TLDG) for reconstruction of digestive tract anastomosis is intra cavitary anastomosis, which does not require auxiliary small incision. The reconstruction of TLDG's anastomosis can have a safer anastomosis regardless of tumor location, with lower incidence of incision problems than LADG, and can be performed better in obese patients $(6,7)$.

Prophylactic drains have been used to remove intraperitoneal collections and to detect complications early. However, numerous trials have failed to demonstrate a reduction of postoperative complications by routine drainage in gastrointestinal $(\mathrm{Gl})$ surgery (8). Several studies performed after open gastrectomy or LADG concluded that the prophylactic use of drains did not improve postoperative outcomes significantly. But there were few studies on routine prophylactic drainage after TLDG.

In the current retrospective study, we compared the outcomes of TLDG with drainage to the outcomes of TLDG without drainage to clarify the value of routine prophylactic drainage in uncomplicated TLDG procedures for distal gastric cancer.

\section{Patients And Methods}

\section{Patients}

We reviewed the outcomes of 420 consecutive patients with distal gastric cancer who underwent TLDG with and without prophylactic drainage at China National Cancer Center/Cancer Hospital from February 2018 to August 2019. Of these, 145 patients who underwent proximal gastrectomy or total gastrectomy, 159 patients who underwent laparoscopic assist surgery, 23 who underwent open gastrectomy (including four cases converted from laparoscopic surgery), and 5 who underwent a simultaneous surgery for other diseases such as choledocholithiasis $(n=1)$, ovarian tumor $(n=1)$, pancreatic tail $(n=3)$ were excluded. 88 patients were included in this study, they were assigned to drain group and no-drain group according to their operation records. Drain group comprised 41 patients who underwent TLDG with routine prophylactic drainage and no-drain group comprised 47 patients who underwent TLDG without routine prophylactic drainage. Figure 1 CONSORT diagrams. Flowchart of the patients assessed in this study 


\section{Totally Laparoscopic Distal Gastrectomy}

The extent of gastrectomy and lymph node dissection was determined based on the Japanese gastric cancer treatment guidelines (9). The operator was on the left side of the patient to finish laparoscopic ligation and division, the first assistant was positioned on the opposite. A cameraman stood between the patients' legs. A five-port system (i.e., two $5 \mathrm{~mm}$ and three $12 \mathrm{~mm}$ ports) was used for each totally laparoscopic distal gastrectomy. $10 \mathrm{~mm}$ flexible laparoscopes were used with $\mathrm{CO} 2$ pressure maintained at $13-15 \mathrm{mmHg}$.

The operator was on the left side of the patient to performed Billroth-I reconstruction using mortified delta-shaped anastomosis(10) or overlap anastomosis(8). Performing Billroth-II or Roux-en-Y reconstruction on the right side of the patients.

\section{Postoperative Management}

Patients in both groups were given prophylactic antibiotics half an hour before surgery. The decision of whether to use a prophylactic drain was made by the surgeon. Oral intake of water was initiated on the first day after the surgery. Soft diet was initiated after patient could tolerate liquid meals and postoperative UGIs confirmed the absence of anastomotic leakage.

\section{Outcome Assessment}

The clinical, operative, and pathological variables were compared between the two groups based on the information obtained from our prospectively collected surgical database. Early postoperative complications (occurring on postoperative days 0-30) were graded using the Clavien-Dindo classification. Early postoperative complications requiring medical, radiological, or surgical interventions (grade 2 or higher) were regarded as an event. The occurrence of postoperative complication risk was also assessed.

\section{Statistical Analysis}

All values were expressed as mean \pm SD. Using $\chi 2$ test and Student's $t$ test for comparing the clinical characteristics categorical variables and continuous variables, respectively. For categorical data, the chisquared test or Fisher's exact test is performed. A P value of $<0.05$ was considered significant. Statistical analysis was performed using the SPSS. 20 .

\section{Results}

\section{Patient Characteristics}


Table 1 shows the clinical characteristics of patients undergoing TLDG with or without prophylactic drain. Between two groups no significant differences were observed in patient sex, age, BMI, ASA-PS, pTstage, pNstage, the number of patients with a previous abdominal operation, and the number receiving neoadjuvant chemotherapy, only in preoperative concurrent illness, the drain group was significantly higher than the no-drain group $(48.8 \%$ vs. $27.7 \%, p<0.05)$.

Table 1

The characteristics of patients underwent TLDG with or without prophylactic drain.

\begin{tabular}{|llll|}
\hline Characteristics & Drain $(\mathbf{n}=\mathbf{4 1})$ & Without drain $(\mathbf{n}=47)$ & $\boldsymbol{P}$ \\
\hline Sex $(\mathrm{M} / \mathrm{F})$ & $32 / 9$ & $31 / 16$ & 0.21 \\
\hline Age & $57.78 \pm 9.28$ & $54.15 \pm 12.90$ & 0.138 \\
\hline BMI $\left(\mathrm{kg} / \mathrm{m}^{2}\right)$ & $25.02 \pm 3.55$ & $24.88 \pm 3.60$ & 0.849 \\
\hline ASA $(1 / 2 / 3)$ & & & 0.387 \\
\hline 1 & $1(2.4 \%)$ & $0(0.0 \%)$ & \\
\hline 2 & $37(90.2 \%)$ & $42(89.4 \%)$ & 0.889 \\
\hline 3 & $3(7.3 \%)$ & $5(10.6 \%)$ & \\
\hline pT stage & & & 0.138 \\
\hline T1 & $19(46.4 \%)$ & $23(49 \%)$ & 1.000 \\
\hline T2 & $7(17.1 \%)$ & $11(23.4 \%)$ & 0.041 \\
\hline T3 & $4(9.8 \%)$ & $4(8.5 \%)$ & \\
\hline T4a & $11(26.8 \%)$ & $9(19.1 \%)$ & \\
\hline pN stage & & & \\
\hline N0 & & $13(27.7 \%)$ & \\
\hline N1 & $19(46.3 \%)$ & $20(42.6 \%)$ & \\
\hline N2 & $7(17.1 \%)$ & $12(25.5 \%)$ & \\
\hline N3 & $7(17.1 \%)$ & $6(12.8 \%)$ & \\
\hline Previous abdominal operation & $6(14.6 \%)$ & $9(19.1 \%)$ & \\
\hline Neoadjuvant chemotherapy & $2(4.9 \%)$ & $2(4.3 \%)$ & \\
\hline Concurrent illness & $20(48.8 \%)$ & $13(27.7 \%)$ & \\
\hline ASA, American Society of Anesthesiologists; BMl, body mass index & \\
\hline
\end{tabular}




\section{Operative Findings}

Operative outcomes are summarized in Table 2. More operating time cost in the drain group than in the no-drain group ( $188.10 \pm 38.89 \mathrm{~min}$ vs. $164.30 \pm 36.97 \mathrm{~min}, \mathrm{p}<0.05)$. Mean estimated blood loss and intraoperative blood transfusion were similar between the two groups. There were no significant differences between the two groups in No. of retrieved LNs and tumor size. $(p>0.05)$.

Table 2

Operative findings

\begin{tabular}{|llll|}
\hline Variable & Drain $(\mathbf{n}=\mathbf{4 1})$ & Without drain $(\mathbf{n}=\mathbf{4 7})$ & $\mathbf{P}$ \\
\hline Operation time $(\mathrm{min})$ & $188.10 \pm 38.89$ & $164.30 \pm 36.97$ & 0.004 \\
\hline Estimated blood loss $(\mathrm{ml})$ & $76.83 \pm 58.67$ & $71.70 \pm 52.39$ & 0.666 \\
\hline Intraoperative blood transfusion & $1(2.4 \%)$ & $2(4.3 \%)$ & 1.000 \\
\hline Tumor size & $3.36 \pm 1.65$ & $3.52 \pm 1.37$ & 0.639 \\
\hline No. of retrieved LNs & $39.32 \pm 13.06$ & $39.26 \pm 14.35$ & 0.983 \\
\hline
\end{tabular}

\section{Recovery}

Recovery outcomes are listed in Table 3.The number of days after surgery until the initiation of soft diet ( $5.34 \pm 2.27$ days vs. $4.17 \pm 2.13$ days, $p=0.036)$ and first flatus ( $4.29 \pm 1.45$ days vs. $3.55 \pm 1.83$ days, $p$ $=0.041$ ) were greater in the drain group. There no significant differences were found in first walking time, the length of postoperative hospital stay $(8.15 \pm 2.9$ vs6.77 \pm 2.3 days, $p=0.219)$ between two group. Postoperative CRP $(8.24 \pm 4.47$ vs. $8.67 \pm 5.97, p>0.05)$ and $\operatorname{Tmax}\left(37.6 \pm 0.6^{\circ} \mathrm{Cvs} .37 .5 \pm 0.4^{\circ} \mathrm{Cp}>0.05\right)$ were similar between the two groups.

Table 3

Recovery

\begin{tabular}{|llll|}
\hline Variable & Drain $(\mathbf{n}=\mathbf{4 1})$ & Without drain $(\mathbf{n}=47)$ & $\mathbf{P}$ \\
\hline First walking, POD & $3.05 \pm 1.482$ & $3.06 \pm 1.36$ & 0.960 \\
\hline First flatus, POD & $4.29 \pm 1.45$ & $3.55 \pm 1.83$ & 0.041 \\
\hline First eating soft diet, POD & $5.34 \pm 2.27$ & $4.17 \pm 2.13$ & 0.014 \\
\hline Postoperative hospital stay & $8.15 \pm 5.2$ & $6.77 \pm 5.24$ & 0.219 \\
CRP & $8.24 \pm 4.47$ & $8.67 \pm 5.97$ & 0.705 \\
\hline Tmax & $37.6 \pm 0.6$ & $37.5 \pm 0.4$ & 0.402 \\
\hline
\end{tabular}




\section{Short-time Outcomes}

Postoperative patient complications are listed in Table 4. No mortality was recorded for both groups. The overall postoperative complication rate was $19.5 \%$ in the drain group, and $10.6 \%$ in the no-drain group (p $>0.05$ ). There were no anastomotic bleeding, anastomotic Leakage, lymph leakage, lleus and pancreatic fistula occur in either group. Clavien-Dindo grade 3 complication comprise duodenal stump leakage $(n=$ $2)$, intra-abdominal abscess $(n=2)$ and intra-abdominal bleeding $(n=1)$ in the drainage group. The need for PCD was not significantly different between groups ( $9.8 \%$ vs. $6.4 \%, p=0.700)$.

Table 4

Postoperative complications

\begin{tabular}{|llll|}
\hline Complications & Drain $(\mathbf{n = 4 1 )}$ & Without drain $(\mathbf{n}=47)$ & $\boldsymbol{P}$ \\
\hline Total & $8(19.5 \%)$ & $5(10.6 \%)$ & 0.242 \\
\hline Clavien-Dindo grade II & & & \\
\hline Incision & $0(0.0 \%)$ & $1(2.1 \%)$ & \\
\hline System complications & $1(2.4 \%)$ & $1(2.1 \%)$ & \\
\hline Abdominal effusion & $2(4.9 \%)$ & $0(0.0 \%)$ & \\
\hline Clavien-Dindo grade III & & & \\
\hline Duodenal stump leakage & $2(4.9 \%)$ & $0(0.0 \%)$ & \\
\hline Intra-abdominal bleeding & $1(2.4 \%)$ & $0(0.0 \%)$ & 1.000 \\
\hline Intra-abdominal abscess & $2(4.9 \%)$ & $2(4.2 \%)$ & 0.700 \\
\hline Pleural effusion & $0(0.0 \%)$ & $1(2.1 \%)$ & \\
\hline Mortality & $0(0.0 \%)$ & $0(0.0 \%)$ & \\
\hline Need for PCD & $4(9.8 \%)$ & $3(6.4 \%)$ & \\
\hline PCD, percutaneous catheter drainage & & \\
\hline
\end{tabular}

\section{Risk Assessment For The Occurrence Of Postoperative Complication}

Postoperative complication risk factors are listed in Table 5. Between two groups no significant differences were observed in majority of variables, only patients with larger BMI had a higher possibility of postoperative complication ( $27.38 \pm 4.27$ vs. $24.53 \pm 3.27, p=0.007)$. In addition, we identified that patients with $B M I \geq 29$ are prone to postoperative complications $(p=0.042)$. A prophylactic drain may thus be useful in patients at higher risk and in those with larger BMI or more concurrent illness. 
Table 5

Risk assessment for the occurrence of postoperative complication

\begin{tabular}{|c|c|c|c|}
\hline Variable & $\begin{array}{l}\text { Postoperative complication } \\
(+) \\
(n=13)\end{array}$ & $\begin{array}{l}\text { Postoperative complication } \\
(-) \\
(n=75)\end{array}$ & $P$ \\
\hline $\operatorname{Sex}(M / F)$ & $10 / 3$ & $53 / 22$ & 0.751 \\
\hline Age & $59.69 \pm 10.27$ & $55.17 \pm 11.56$ & 0.168 \\
\hline $\mathrm{BMI}\left(\mathrm{kg} / \mathrm{m}^{2}\right)$ & $27.38 \pm 4.27$ & $24.53 \pm 3.27$ & 0.007 \\
\hline$\geq 29$ & $5(38.5 \%)$ & 10(13.3) & 0.042 \\
\hline$<29$ & $8(61.5)$ & $65(86.7)$ & \\
\hline $\operatorname{ASA}(1 / 2 / 3)$ & & & 0.439 \\
\hline 1 & $0(0.0 \%)$ & $1(1.3 \%)$ & \\
\hline 2 & $11(84.6 \%)$ & $68(90.7 \%)$ & \\
\hline 3 & $2(15.4 \%)$ & $6(8.0 \%)$ & \\
\hline Preoperative ALB (g) & $36.34 \pm 9.91$ & $37.77 \pm 5.04$ & 0.460 \\
\hline Preoperative HGB (g/L) & $111.80 \pm 19.99$ & $120.81 \pm 19.51$ & 0.205 \\
\hline pT stage & & & 0.736 \\
\hline T1 & $5(38.5 \%)$ & $37(49.3 \%)$ & \\
\hline T2 & $3(23.1 \%)$ & $15(20.0 \%)$ & \\
\hline T3 & $2(15.4 \%)$ & $6(8.0 \%)$ & \\
\hline $\mathrm{T} 4 \mathrm{a}$ & $3(23.1 \%)$ & $17(22.7 \%)$ & \\
\hline pN stage & & & 0.728 \\
\hline No & $5(38.5 \%)$ & $34(45.3 \%)$ & \\
\hline N1 & $2(15.4 \%)$ & $17(22.7 \%)$ & \\
\hline N2 & $3(23.1 \%)$ & $10(13.3 \%)$ & \\
\hline N3 & $3(23.1 \%)$ & 14(18.7\%) & \\
\hline $\begin{array}{l}\text { Previous abdominal } \\
\text { operation }\end{array}$ & $1(7.7 \%)$ & $18(24.0 \%)$ & 0.283 \\
\hline Neoadjuvant chemotherapy & $2(15.4 \%)$ & $2(2.7 \%)$ & 0.102 \\
\hline Concurrent illness & $6(46.2 \%)$ & $27(36.0 \%)$ & 0.485 \\
\hline
\end{tabular}




\begin{tabular}{|c|c|c|c|}
\hline Variable & $\begin{array}{l}\text { Postoperative complication } \\
(+) \\
(n=13)\end{array}$ & $\begin{array}{l}\text { Postoperative complication } \\
(-) \\
(n=75)\end{array}$ & $P$ \\
\hline Type of reconstruction & & & 0.196 \\
\hline Billroth I & $4(30.8 \%)$ & $27(36.0 \%)$ & \\
\hline Billroth II & $8(61.5 \%)$ & $48(64.0 \%)$ & \\
\hline Roux-en-Y & $1(7.7 \%)$ & $0(0.0 \%)$ & \\
\hline Operative time (min) & $185.39 \pm 46.89$ & $173.65 \pm 38.18$ & 0.326 \\
\hline Blood loss (ml) & $63.08 \pm 47.50$ & $76.00 \pm 56.43$ & 0.439 \\
\hline
\end{tabular}

\section{Discussion}

Since 2015 , totally laparoscopic surgery has been widely used in clinical practice, but there are few articles on whether totally laparoscopic surgery requires prophylactic drains $(10,11)$. Most of studies about prophylactic drains were based on open gastrectomy, Cochrane review by Wang et al., which included four single-institution, randomized controlled trials that sought to evaluate the role of PD placement in the setting of any type of gastric resection for gastric cancer (12-14). In this study, we reviewed the clinicopathological data of gastric cancer patients in our treatment group during the past two years, and found that routine prophylactic drains were not necessary in selective patients. A prophylactic drain may be useful in patients at higher risk.

It is generally believed that prophylactic drains are used to enhance early detection of complications, prevent collection of fluid, reduce morbidity and mortality, and decreases the duration of hospital stay (15, 16), the present study results had shown that there was no significant difference between two groups in postoperative hospital stay, while there was a trend: the length of postoperative hospital stay in no drain group was shorter than in drain group $((8.15 \pm 2.9$ vs $6.77 \pm 2.3$ days, $p>0.05)$. Among the 13 patients who experienced postoperative complications, there was also no significant difference between two groups in postoperative hospital stay. This result was different with Hirahara N et al.'s (10) study. In addition, without using prophylactic drainage can significantly improve the postoperative comfort of patients, earlier flatus ( $4.29 \pm 1.45$ days vs. $3.55 \pm 1.83$ days, $p<0.05)$ and feeding with soft meal $(5.34 \pm 2.27$ days vs. $4.17 \pm 2.13$ days, $p<0.05)$.

Moreover, the application of Prophylactic drains does not reduce the incidence of complications, and complications were even higher in the drain group, although there was no statistically significant difference $(19.5 \%$ vs. $10.6 \%, p>0.05)$. By risk assessment, we identified that patients with $B M I \geq 29$ are prone to postoperative complications $(p=0.042)$. It is important to note that there are a variety of causes of the results, on the one hand, this is a retrospective study, differences between two groups of data in 
concurrent illness maybe lead to more postoperative complications in drain group; On the other hand, the difference may not be statistically significant due to the insufficient number of cases.

For patients with mild symptoms, administration of broad-spectrum antibiotics could be a good conservative management strategy, but for patients with severe symptoms, they need PCD. In the current study, postoperative complications were recognized in about $15 \%$ of patients. 2 cases of duodenal stump leakage and 2 cases of intra-abdominal abscess occur in drain group, all these cases needed PCD. In the no-drain group, 2 case of intra-a bdominal abscess and 1 case of pleural effusion needed a PCD. There was no significant difference between two groups. Prophylactic drains do not altering rates of secondary drainage procedures. In conclusion, without PD during gastric cancer surgery doesn't increase the risk of PCD postoperatively.

\section{Conclusion}

In conclusion, without using PD in selective patients during gastric cancer surgery is possible which can significantly improve the postoperative comfort of patients and doesn't increase risk of postoperative complications.

\section{Limitations}

Here is a retrospective study, selection bias is unavoidable, for example the differences between two groups of data in concurrent illness maybe lead to more postoperative complications in drain group, and the decision regarding whether to use a PD is decided by surgeon. Another limitation is that this study only enrolled the patients undergone gastrectomy in our center during the last two years, which means results are not universal. Thus, we are going to perform a randomized, controlled trial to compare the outcomes between routinely used PD group and selectively used PD based on the present study.

\section{Declarations}

\section{Ethics approval and consent to participate}

This study was approved by the Institutional Review Board at the Cancer Hospital of the Chinese Academy of Medical Sciences. Written informed consent was obtained from all patients, and the data were anonymously analyzed.

\section{Consent for publication}

Not applicable.

\section{Availability of data and material}

The datasets supporting the conclusions of this article are available from the corresponding author on demand. 


\section{Competing interests}

The authors declare that they have no competing interests.

\section{Funding}

This work was supported by National Natural Science Foundation of China (grant number, 81772642), Beijing Municipal Science \& Technology Commission (grant number, Z161100000116045); and Capital's Funds for Health Improvement and Research (grant number, CFH 2018-2-4022).

The funding body did not contribute to the design of the study and collection, analysis, and interpretation of data, or in writing the manuscript.

Author contributions: Hao Liu and Peng Jin contributed equally to this work and they were involved in concept, data interpretation, wrote the first draft, and revised it critically in light of comments from other authors; Quan Xu and Fuhai Ma analyzed the data. Shuai Ma and Yibin Xie collected the patient's clinical data. Yantao Tian was involved in study conception and design, data interpretation, manuscript revision, and discussion; all authors approved the final version submitted.

\section{Acknowledgements}

Not applicable.

\section{References}

1. Bray F, Ferlay J, Soerjomataram I, et al. Global cancer statistics 2018: GLOBOCAN estimates of incidence and mortality worldwide for 36cancers in 185 countries. CA Cancer J Clin. 2018 Nov;68(6):394-424.

2. Chen W, Zheng R, Baade PD, et al. Cancer statistics in China, 2015[J]. CA Cancer J Clin. 2016;66(2):115-32.

3. Kitano S, Iso Y, Moriyama M, et al. Laparoscopy-assisted Billroth I gastrectomy. Surg Laparosc Endosc. 1994;4(2):146-8.

4. Kim H-H, Hyung WJ, Cho GS, et al. Morbidity and mortality of laparoscopic gastrectomy versus open gastrectomy for gastric cancer: an interim report-a phase III multicenter, prospective, randomized Trial (KLASS Trial). Annals of surgery. 2010;251(3):417-20.

5. Yu J, Huang C, Sun Y, et al, Chinese Laparoscopic Gastrointestinal Surgery Study (CLASS) Group. Effect of Laparoscopic vs Open Distal Gastrectomy on 3-Year Disease-Free Survival in Patients With Locally Advanced Gastric Cancer: The CLASS-01 Randomized Clinical Trial. JAMA. 2019 May;28(20):1983-92. 321.

6. Kim MG, Kawada H, Kim BS, et al. A totally laparoscopic distal gastrectomy with gastroduodenostomy (TLDG) for improvement of the early surgical outcomes in high BMI patients. Surg Endosc. 2011;25(4):1076-82. 
7. Kim MG, Kim KC, Kim BS, et al. A totally laparoscopic distal gastrectomy can be an effective way of performing laparoscopic gastrectomy in obese patients (body mass index $>/=30$ ). World J Surg. 2011;35(6):1327-32.

8. Ishikawa K, Matsumata T, Kishihara F, et al. Laparoscopy-assisted distal gastrectomy for early gastric cancer with versus without prophylactic drainage. Surg Today. 2011;41:1049-53.

9. Japanese Gastric Cancer Association. Japanese gastric cancer treatment guidelines 2014 (ver.4). Gastric Cancer. 2016;20:1-19.

10. Hirahara N, Matsubara $\mathrm{T}$, Hayashi $\mathrm{H}$, et al. Significance of prophylactic intra-abdominal drain placement after laparoscopic distal gastrectomy for gastric cancer. World J Surg Oncol. 2015;13:181.

11. Shimoike N, Akagawa S, Yagi D, et al. Laparoscopic gastrectomy with and without prophylactic drains in gastric cancer: a propensity score-matched analysis. World J Surg Oncol. 2019 Aug;16(1):144. 17(.

12. Alvarez Uslar R, Molina $\mathrm{H}$, Torres $\mathrm{O}$, et al. Total gastrectomy with or without abdominal drains. A prospective randomized trial. Rev Esp Enferm Dig. 2005 Aug;97(8):562-9.

13. Kumar M, Yang SB, Jaiswal VK,et al. Is prophylactic placement of drains necessary after subtotal gastrectomy? World J Gastroenterol. 2007 Jul 21;13(27):3738-41.

14. Kim J, Lee J, Hyung WJ, et al. Gastric cancer surgery without drains: a prospective randomized trial. J Gastrointest Surg. 2004 Sep-Oct;8(6):727-32.

15. Messager M, Sabbagh C, Denost Q, et al. Is there still a need for prophylactic intra-abdominal drainage in elective major gastro-intestinal surgery? J Visc Surg. 2015 Nov;152(5):305-13.

16. Lee J, Choi YY, An JY, et al. Do All Patients Require Prophylactic Drainage After Gastrectomyfor Gastric Cancer? The Experience of a High-Volume Center. Ann Surg Oncol. 2015 Nov;22(12):392937.

\section{Figures}




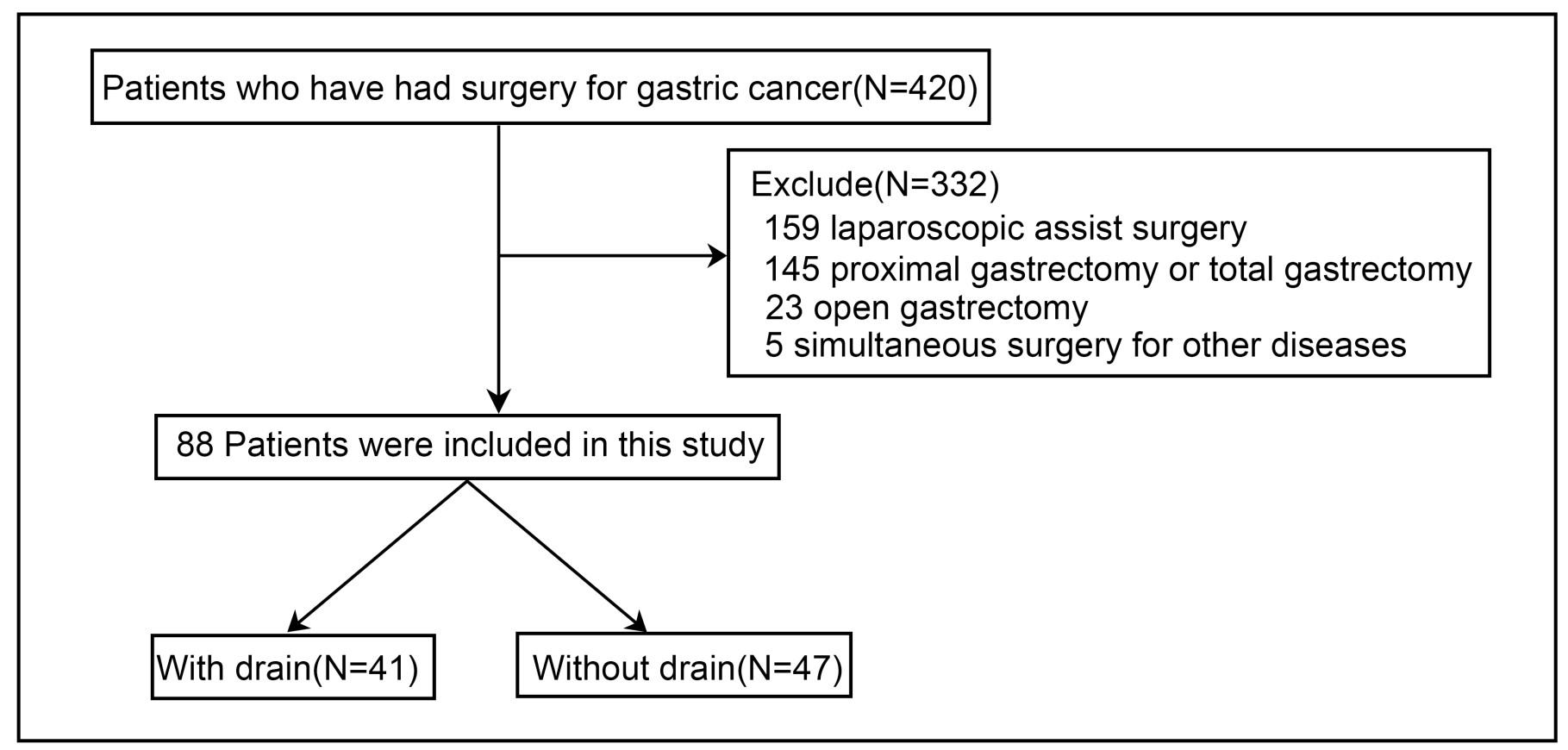

Figure 1

CONSORT diagrams. Flowchart of the patients assessed in this study 